\title{
IMPACT ASSESSMENT OF MIKANIA MICRANTHA ON LAND COVER AND MAXENT MODELING TO PREDICT ITS POTENTIAL INVASION SITES
}

\author{
Tina Baidar ${ }^{\mathrm{a}}$, Anu Bhalu Shrestha ${ }^{\mathrm{a}}$, Rita Ranjit ${ }^{\mathrm{b}}$, Ruby Adhikari ${ }^{\mathrm{c}}$, Subash Ghimire ${ }^{\mathrm{d}}$, Nawaraj Shrestha ${ }^{\mathrm{d}}$ \\ ${ }^{a}$ Survey Department, Nepal - tina.baidar13@gmail.com, shrestha.anu17@gmail.com \\ ${ }^{\mathrm{b}}$ Technical Resources International Inc, USA - rita.ranjit23@gmail.com \\ ${ }^{\mathrm{c}}$ Nepalese Army, Survey Mahasakha, Nepal - adhikariruby1234@gmail.com \\ ${ }^{\mathrm{d}}$ Department of Civil and Geomatics Engineering, Kathmandu University, Nepal - subash_ghimire@ku.edu.np, \\ nawa.shrestha@ku.edu.np
}

KEY WORDS: Mikania micrantha, Invasive Species, Chitwan National Park, Image Classification, Maxent Modeling

\begin{abstract}
:
Mikania micrantha is one of the major invasive alien plant species in tropical moist forest regions of Asia including Nepal. Recently, this weed is spreading at an alarming rate in Chitwan National Park (CNP) and threatening biodiversity. This paper aims to assess the impacts of Mikania micrantha on different land cover and to predict potential invasion sites in CNP using Maxent model. Primary data for this were presence point coordinates and perceived Mikania micrantha cover collected through systematic random sampling technique. Rapideye image, Shuttle Radar Topographic Mission data and bioclimatic variables were acquired as secondary data. Mikania micrantha distribution maps were prepared by overlaying the presence points on image classified by object based image analysis. The overall accuracy of classification was $90 \%$ with Kappa coefficient 0.848 . A table depicting the number of sample points in each land cover with respective Mikania micrantha coverage was extracted from the distribution maps to show the impact. The riverine forest was found to be the most affected land cover with $85.98 \%$ presence points and sal forest was found to be very less affected with only $17.02 \%$ presence points. Maxent modeling predicted the areas near the river valley as the potential invasion sites with statistically significant Area Under the Receiver Operating Curve (AUC) value of 0.969. Maximum temperature of warmest month and annual precipitation were identified as the predictor variables that contribute the most to Mikania micrantha's potential distribution.
\end{abstract}

\section{INTRODUCTION}

Species invasion is profoundly altering communities and ecosystems worldwide (Gurevitch and Padilla, 2004). The Convention on Biological Diversity (CBD), underlines that the biological invasion of alien species is the second worst threat after habitat destruction and set global priorities and guidelines to collect information and coordinate international actions on invasive alien species management. Invasive alien species (IAS) is an alien species, which becomes established in natural or seminatural ecosystems or habitat, an agent of change, and threatens native biological diversity (IUCN, 2000). An IAS has the potential to alter the structure and function of natural ecosystems in a significant way. This paper encompasses Mikania micrantha which is an invasive alien plant species (IAPS).

Mikania micrantha (commonly known as Mile-a-minute weed) is a native of Central and South America ("Global Invasive Species Database," 2014). It is one of the major IAPS in many tropical moist forest regions of Asia including Nepal. Nepal is a country with high climatic and physiographic diversity because of which plant and animal from any part of the world may find a suitable habitat here. Tiwari et al. (2005) listed 166 alien plant species which accounts $2.59 \%$ of the reported 6419 flowering plant species in Nepal. Among them, 21 species have been considered important with various levels of impacts on biodiversity and ecosystems under which Mikania micrantha is serious invasive alien plant species disrupting forests and shrublands. Commonly known as Lahare banmara in Nepal, it is one of the "High Risk
Posed Invasive Alien Plant Species (IAPS) of Nepal" (Tiwari et al., 2005). It is the most frequently encountered IAPS with high coverage in eastern and central part of Nepal.

It is generally agreed that infestation by IAS alters community structure and ecosystem processes (Bhoju et al., 2012). However, approaches taken to combat invasive species and even the data on which they should be based are clearly inadequate to deal with the onslaught of invasive species in Nepal (Kunwar et al., 2013). Nepal is a signatory to the CBD. Article8 (h) of the convention calls upon its contracting parties, as far as possible and as appropriate, to "prevent the introduction of, control, or eradicate those alien species which threaten ecosystems, habitats or species".

A few case studies in Nepal have indicated that IAS reduces species diversity and negatively affect forest regeneration. Papers on the study of Mikania micrantha in CNP have presented its impact on different species of flora and fauna. This paper aims to determine its potential invasion sites which can help in adapting control and preventive measures of the weed. The objectives of this paper are to:

- Study the impact posed by Mikania micrantha on different land cover of study area such as grassland, riverine forest and sal forest.

- Determine potential invasion sites in CNP using Maxent model. 


\section{STUDY AREA}

This paper is based on the study performed in Chitwan National Park (CNP) and Buffer Zone Community Forest (BZCF) of Bachhauli VDC. The park is situated in the sub-tropical lowlands of southern central part of Nepal covering a total area of 932 sq. km. In 1984, the Chitwan National Park was included on the list of World Heritage Site by UNESCO (DNPWC, n.d.). Bachhauli VDC, with an area of 19.3 sq. km is located at north of the National park. The land cover consists of riverine forest, grassland and agricultural land.

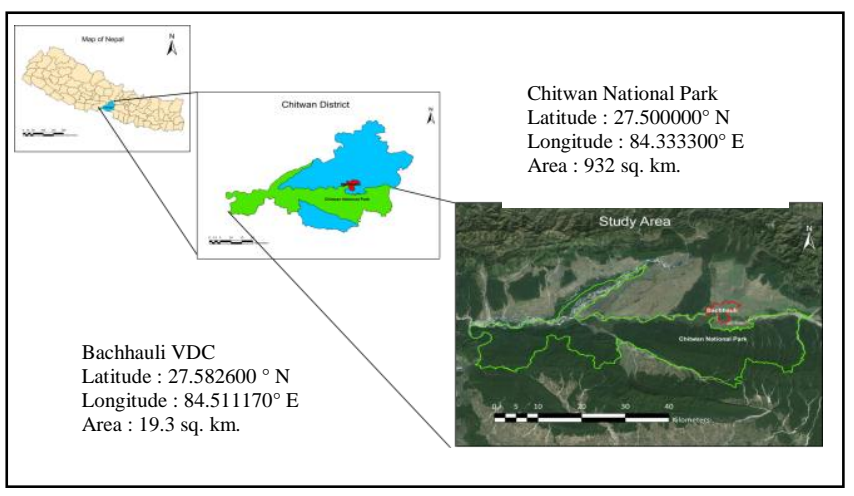

Figure 1. Study area

Mikania micrantha is witnessed to have been expanding at a very alarming rate in CNP (Paudel, 2011). This weed has been creating a serious threat by suppressing the growth of native plants and preventing the regenerations of other plants due to its high dispersal ability (by winds, animals, and by its own natural expansion) and adaptability to colonize in new habitat (Ram, 2008). As we know that CNP is very rich in biodiversity if this species of IAPS goes on invading in this rate it may create threats to the whole ecosystem.

\section{METHODOLOGY}

\subsection{Data Collection}

The primary data were the Global Positioning System (GPS) location of sample points in the study area. Systematic random sampling technique with sampling interval $200 \mathrm{~m}$ was used to collect the sample points in the selected BZCF. At each sample point, the coordinates of that point were recorded using handheld GPS. For the impact assessment purpose, the distribution of Mikania micrantha was observed within a circular plot of approximately $50 \mathrm{~m}$ radius around each point. The distribution was then classified into four different levels: $0,1,2$, and 3 representing $0 \%$, less than $50 \%$, more than $50 \%$, and $100 \%$ presence of species respectively. For sampling in the core area, similar method with $500 \mathrm{~m}$ sampling interval was used.

The secondary data includes Rapid eye satellite image of $5 \mathrm{~m}$ resolution which was collected from Forest Resource Assessment (FRA), Nepal. Along with this, topographic data including administrative boundary, road and river of Chitwan district was obtained from Survey Department (DoS), Nepal.

\subsection{Image Classification and Accuracy Assessment}

Two-third portion of sample points were used to train the image classification algorithm, leaving one-third samples as a test dataset for assessing classification accuracy using proportional stratified random sampling technique. Object based image classification technique was used to classify the image. Multiresolution segmentation algorithm was chosen for image segmentation. The parameters were defined through trial and error to successfully segment objects in an image. Segmentation outputs were visually checked in relation to target class (e.g., forest area or grassland) to evaluate which parameter combinations best captured the objects of interest.

The image objects created by segmentation were classified to give them both a meaning and a label. User defined decision rules or rule sets were developed by using the information within the image and the properties of the objects. The classification was applied using a "top-down" approach. That is, the classification started from very general classes, which were further subdivided into more specific classes. The final classification of the image resulted in seven land cover classes namely Sal Forest, Riverine Forest, Grassland, Water Bodies, Sand, Agricultural Land, and Bare Land. The accuracy assessment of image classification was performed by creating confusion matrix.

\subsection{Mapping for Impact Assessment}

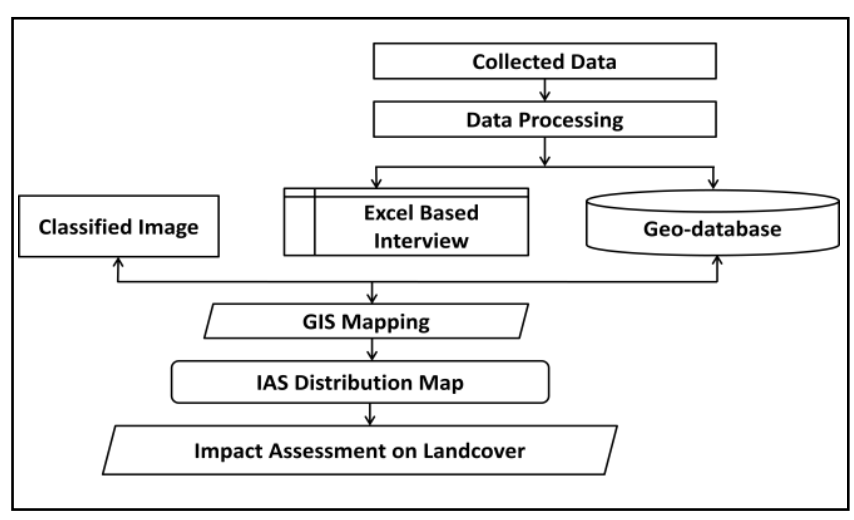

Figure 2. Work flow diagram for distribution mapping

To prepare the distribution map, the GPS coordinates of all the samples were overlaid on the classified image. Then the buffer of $50 \mathrm{~m}$ radius for each sampling point was generated. The buffered points were symbolized in a graduated manner according to their distribution i.e. presence of Mikania micrantha $0 \%,<50 \%,>50 \%$ and $100 \%$ with the darker colour representing higher presence.

\subsection{Suitability Analysis through Maxent Model}

Maxent modeling uses a set of occurrence localities, together with a set of environmental variables that describe some of the factors that likely influence the suitability of the environment for the species (Phillips et al., 2006). 19 bioclimatic variables with 30 arc seconds spatial resolution were downloaded from World-Clim 
dataset provided in www.worldclim.org_website. Data for altitude, precipitation, maximum, minimum, and mean temperatures of the same resolution were also downloaded from the same source. The Shuttle Radar Topographic Mission (SRTM) Digital Terrain Model (DTM) with $90 \mathrm{~m}$ resolution, downloaded from the www.srtm.usgs.gov website, was used to generate the slope, aspect and elevation data layers. The layers representing distance from road and river were also generated.

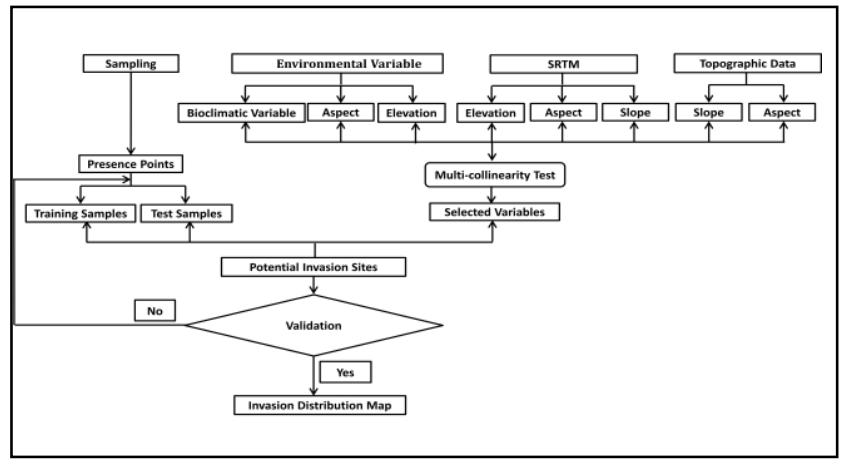

Figure 3. Work flow diagram for Maxent modeling

All the variables were tested for multi-collinearity by examining cross-correlations among them. Multi-collinearity test was conducted based on the values of correlation coefficient (r). Only one variable from a set of highly cross-correlated variables ( $r$ \pm 0.8 ) (Yang et al., 2013) was included in the model based on the potential biological relevance to the distribution of the species. Out of 28 variables, only 10 were selected as predictor variables. Among the 10 variables, 8 were non-collinear (Bio2, Bio5, Bio10, Bio3, Bio8, Ri_dist and Ro_dist) while the other 2 variables (Bio1 and Bio12) accounted for all the remaining variables since they were highly correlated.

For prediction, all the selected variables were used as input in the model. Two-third data from the total samples were used as training datasets and one-third as test datasets to run the model. For each run, the AUC (Area under the Response Curve) was assessed that determines the accuracy of the model.

\begin{tabular}{|l|l|l|l|}
\hline S.N & Code & Environmental Variables & Unit \\
\hline $\mathbf{1}$ & Bio1 & Annual mean temperature* & ${ }^{\circ} \mathbf{C}$ \\
\hline $\mathbf{2}$ & Bio2 & $\begin{array}{l}\text { Mean diurnal range (mean of } \\
\text { monthly max. and min. temp.) }\end{array}$ & ${ }^{\circ} \mathbf{C}$ \\
\hline $\mathbf{3}$ & Bio3 & Isothermality (Bio2/Bio7) $\times 100)$ & - \\
\hline 4 & Bio4 & Temperature seasonality (std. & C of V \\
\hline $\mathbf{5}$ & Bio5 & Maximum temperature of warmest & ${ }^{\circ} \mathbf{C}$ \\
\hline 6 & Bio6 & Minimum temperature of coldest & ${ }^{\circ} \mathrm{C}$ \\
\hline 7 & Bio7 & Temperature annual range $($ Bio5- & ${ }^{\circ} \mathrm{C}$ \\
\hline $\mathbf{8}$ & Bio8 & Mean temperature of wettest & ${ }^{\circ} \mathbf{C}$ \\
\hline 9 & Bio9 & Mean temperature of driest quarter & ${ }^{\circ} \mathrm{C}$ \\
\hline $\mathbf{1 0}$ & Bio10 & Mean temperature of warmest & ${ }^{\circ} \mathbf{C}$ \\
\hline 11 & Bio11 & Mean temperature of coldest quarter & ${ }^{\circ} \mathrm{C}$ \\
\hline $\mathbf{1 2}$ & Bio12 & Annual precipitation & $\mathbf{M m}$ \\
\hline 13 & Bio13 & Precipitation of wettest period & $\mathrm{Mm}$ \\
\hline 14 & Bio14 & Precipitation of driest period & $\mathrm{Mm}$ \\
\hline 15 & Bio15 & Precipitation seasonality $(\mathrm{CV})$ & $\mathrm{C}$ of V \\
\hline 16 & Bio16 & Precipitation of wettest quarter & $\mathrm{Mm}$ \\
\hline
\end{tabular}

\begin{tabular}{|l|l|l|l|}
\hline 17 & Bio17 & Precipitation of driest quarter & $\mathrm{Mm}$ \\
\hline 18 & Bio18 & Precipitation of warmest quarter & $\mathrm{Mm}$ \\
\hline 19 & Bio19 & Precipitation of coldest quarter & $\mathrm{Mm}$ \\
\hline 20 & Tmin & Monthly Minimum Temperature & ${ }^{\circ} \mathrm{C}$ \\
\hline 21 & Tmax & Monthly Maximum Temperature & ${ }^{\circ} \mathrm{C}$ \\
\hline 22 & Tmean & Monthly Mean Temperature & ${ }^{\circ} \mathrm{C}$ \\
\hline 23 & Prec & Precipitation & $\mathrm{Mm}$ \\
\hline 24 & ElE & Elevation & $\mathrm{M}$ \\
\hline $\mathbf{2 5}$ & SlO & Slope & \% rise \\
\hline 26 & ASP & Aspect & \\
\hline $\mathbf{2 7}$ & Ri_dist & Distance from River & M \\
\hline $\mathbf{2 8}$ & Ro_dist & Distance from Road & M \\
\hline
\end{tabular}

Table 1. Environmental variables used in the study

*Note: The variables highlighted in bold format were the ones selected through multi-collinearity test and, then used in modeling as environmental variables.

\section{RESULT AND DISCUSSION}

\subsection{Impact on different Land Cover}

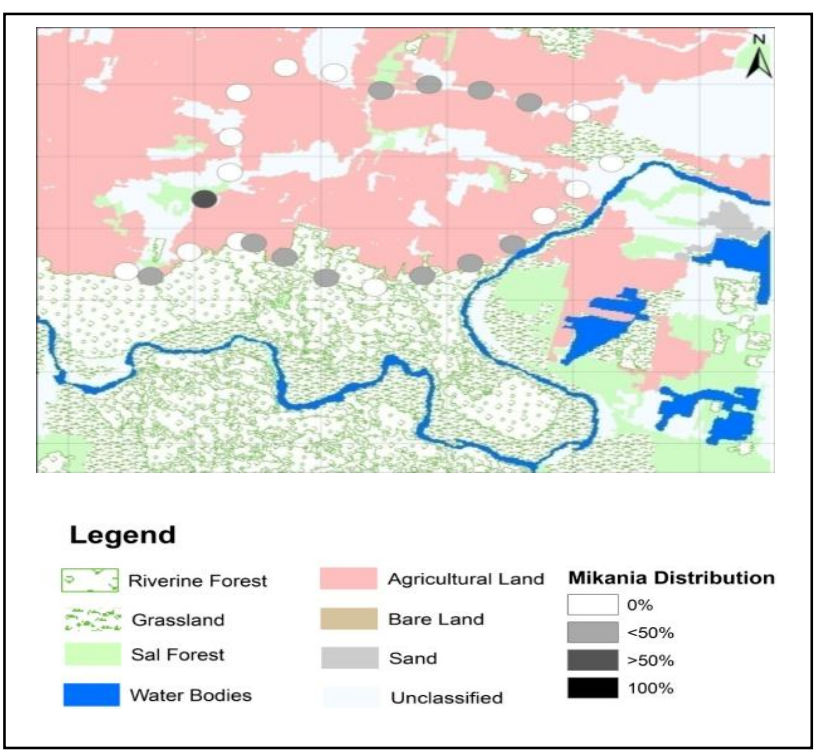

Figure 4. Distribution of Mikania micrantha in Bachhauli VDC

The overall accuracy of the classified map was $90 \%$ with Kappa coefficient 0.848 . From the primary as well as secondary data collected in the field using GPS, the map showing the distribution of Mikania micrantha was prepared. The distribution is shown in graduated colors with $50 \mathrm{~m}$ buffer around each sampling point.

The Table 2 given below is the final result obtained after the analysis of distribution maps, depicting the number of sample points in each land cover system with respective percentage of Mikania micrantha coverage. The total number of sampling points 
collected was 258 where the highest number of points lies in riverine forest whereas the lowest in agricultural land. $66.28 \%$ of points (171) show the presence of Mikania micrantha, where 87 points fall below $50 \%$ coverage, 60 points more than $50 \%$ coverage and 24 points have $100 \%$ coverage.

\begin{tabular}{|l|l|l|l|l|l|}
\hline $\begin{array}{l}\text { Coverage } \\
(\%)\end{array}$ & \multicolumn{2}{|l|}{ Land Cover } & \multicolumn{2}{l|}{} \\
\hline & $\begin{array}{l}\text { Riverine } \\
\text { Forest }\end{array}$ & $\begin{array}{l}\text { Sal } \\
\text { Forest }\end{array}$ & Grassland & $\begin{array}{l}\text { Agricultural } \\
\text { Land }\end{array}$ & Total \\
\hline $100 \%$ & 21 & 1 & 2 & 0 & 24 \\
\hline$>50 \%$ & 51 & 4 & 4 & 1 & 60 \\
\hline$<50 \%$ & 63 & 3 & 15 & 6 & 87 \\
\hline $0 \%$ & 22 & 39 & 17 & 9 & 87 \\
\hline $\begin{array}{l}\text { Total } \\
\text { points }\end{array}$ & 157 & 47 & 38 & 16 & 258 \\
\hline $\begin{array}{l}\text { Presence } \\
\%\end{array}$ & 85.98 & 17.02 & 55.26 & 43.75 & 66.28 \\
\hline
\end{tabular}

Table 2. Number of sample points in different land cover with respective percentage of Mikania micrantha coverage

From the above table, it is concluded that riverine forest has maximum impact of Mikania micrantha that poses the highest risk of invasion within its surrounding. $85.98 \%$ of sample points have presence of Mikania micrantha, whereas sal forest has the least percentage of presence points (17.02\%). Grassland and agricultural land are moderately affected with $55.26 \%$ and $43.75 \%$ presence points respectively.

\subsection{Suitability Analysis of Mikania micrantha}

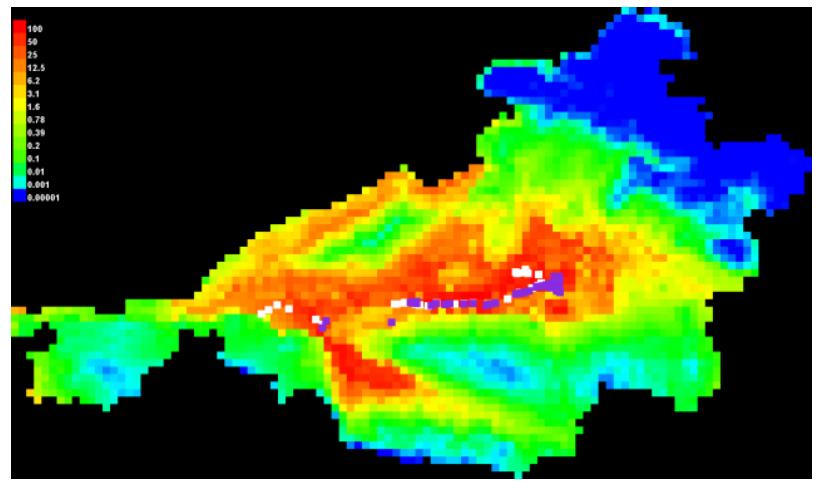

Figure 5. Potential invasion image generated using Maxent model

The output image uses colors to indicate predicted probability that conditions are suitable, with red indicating a high probability of suitable conditions for the species, green indicating conditions typical of those where the species is found and lighter shades of blue indicating low predicted probability of suitable conditions. White dots show the presence locations used for training, while violet dots show test locations.

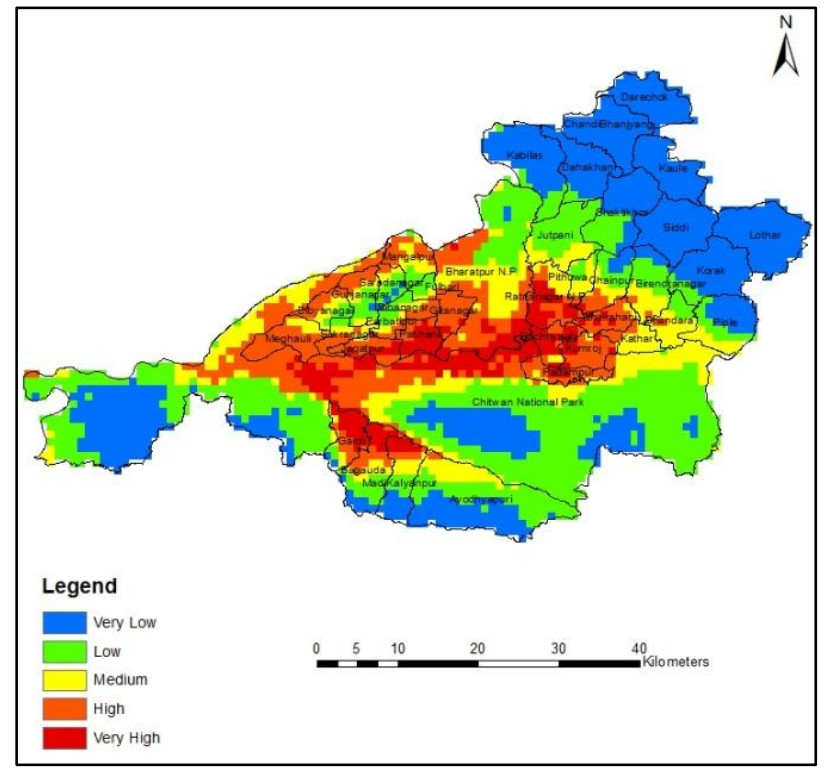

Figure 6. Potential invasion map of Chitwan district

From the potential distribution map, it can be observed that the sites near the river (Rapati, Reu, and Narayani valley) are colored in red, meaning they have very high risk of invasion. The churiya hill slope areas of the national park are colored in mostly green and somewhat blue indicating the lower risk of invasion. This is reasonable with the ground truth that was collected, which showed high level of presence of Mikania micrantha in the riverine forest than any other land cover. Riverine forest is affected mostly because here the weed can get enough moisture, sunlight and support to climb on, which is its suitable habitat. Average presence was seen in grassland since the grass couldn't provide much support to the climber weed which resulted in lesser impact of Mikania micrantha. The least impact is seen in sal forest because sal is a light demanding species and requires complete overhead light from early stages of development. Agricultural land is also shown as suitable habitat for the weed but in ground truth, the land cover is less affected due to continuous human intervention and manual removal of the weed. Maxent model predicts the species fundamental niche rather than realized niche, since it considers only niche-based presence data (Pearson, 2007; Kumar and Stohlgren, 2009). So, the potential distribution areas tend to be over-estimated compared to the realized niche of the species (their habitat). In reality, a species might have failed to disperse due to geographic barriers, human disturbance or associated competitive species.

\subsection{Receiver Operating Characteristic (ROC) Curve}

The Area Under the Receiving Operator Curve (AUC) was used to evaluate model's goodness-of-fit and model with highest AUC value was considered as the best performer. In Figure 7, the red (training) line shows the "fit" of the model to the training data. The blue (testing) line indicates the fit of the model to the testing data, and is the real test of the model's predictive power. The black line shows the line that would be expected if the model was no better than random. If the blue line (the test line) falls below 
the black line then this indicates that the model performs worse than a random model would. The further towards the top left of the graph that the blue line is, the better the model is at predicting the presences contained in the test sample of the data. Since the test line for this model is well above the black line with an AUC value of 0.969 , it is concluded that the model performs well.

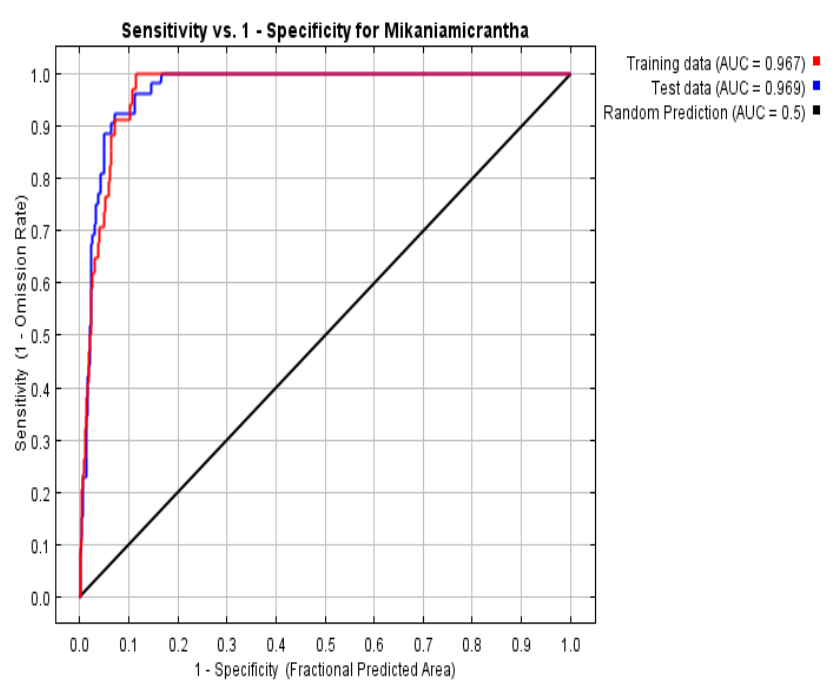

Figure 7. Sensitivity vs. 1-Specificity curve

\subsection{Variable Contributions}

The estimates of relative contributions of the environmental variables to the Maxent model are also given as an output by Maxent (Table 3). Here, the variable, maximum temperature of the warmest month has given the most contribution (53\%) during the modeling for Mikania micrantha. Then, in the second position comes the variable, annual precipitation with $15.5 \%$ contribution.

\begin{tabular}{|c|c|c|}
\hline Variable & $\begin{array}{l}\text { Percent } \\
\text { contribution }\end{array}$ & $\begin{array}{l}\text { Permutation } \\
\text { importance }\end{array}$ \\
\hline $\begin{array}{l}\text { Maximum temperature of warmest } \\
\text { month }\left({ }^{\circ} \mathrm{C}\right)\end{array}$ & 53 & 18.1 \\
\hline Annual precipitation(mm) & 15.5 & 17.3 \\
\hline Distance from Road(m) & 8.7 & 11 \\
\hline Isothermality $((\mathrm{Bio} 2 / \mathrm{Bio} 7) \times 100)$ & 6.7 & 0 \\
\hline Distance from River(m) & 4.4 & 0.8 \\
\hline $\begin{array}{l}\text { Mean temperature of warmest } \\
\text { quarter }\left({ }^{\circ} \mathrm{C}\right)\end{array}$ & 3.8 & 0.6 \\
\hline $\begin{array}{l}\text { Mean diurnal range (mean of } \\
\text { monthly max. and min. temp.) }\left({ }^{\circ} \mathrm{C}\right)\end{array}$ & 3.5 & 13.6 \\
\hline $\begin{array}{l}\text { Mean temperature of wettest } \\
\text { quarter }\left({ }^{\circ} \mathrm{C}\right)\end{array}$ & 2.4 & 35.3 \\
\hline Slope & 2 & 3.2 \\
\hline Annual mean temperature $\left({ }^{\circ} \mathrm{C}\right)$ & 0 & 0 \\
\hline
\end{tabular}

Table 3. Analysis of variable contributions

To get alternate estimates of which variables are most important in the model, a jackknife test was also run. The following Figure 8 shows the results of the jackknife test of variable importance.
The environmental variable with highest gain when used in isolation is bio5, which therefore appears to have the most useful information by itself. The environmental variable that decreases the gain the most when it is omitted is bio12, which therefore appears to have the most information that isn't present in the other variables.

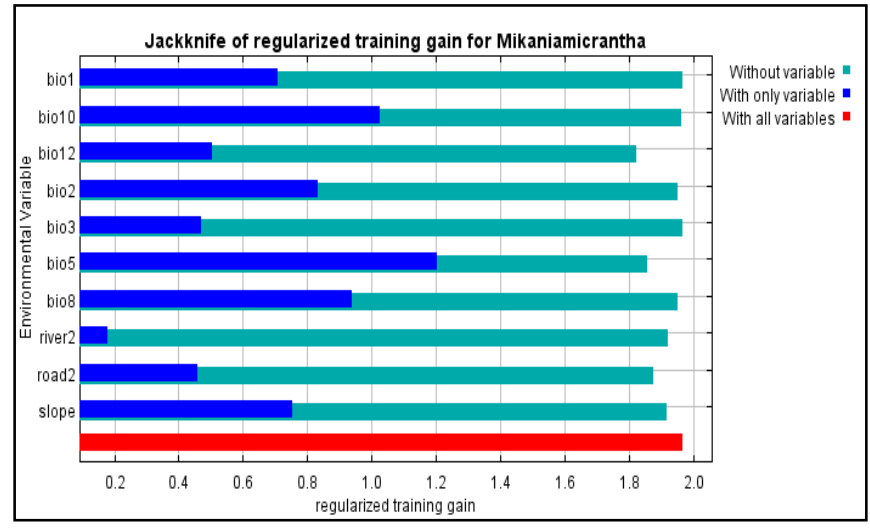

Figure 8: Jackknife of Regularized Training Gain for Mikania micrantha

Therefore, from both of the above analysis, it is concluded that bio5 i.e. Maximum Temperature of warmest month and bio12 i.e. Annual precipitation have more contribution for predicting the potential invasion of Mikania micrantha.

\section{CONCLUSION AND RECOMMENDATION}

This paper has assessed the impacts of Mikania micrantha on land cover and predicted the potential invasion sites in CNP through Maxent modeling successfully. This research aimed to provide a brief overview of the extent to which Mikania micrantha can invade the national park if no intervention is applied. The present study complements previous studies of impacts of various invasive species; however, the attempt to model Mikania micrantha invasion potential at $\mathrm{CNP}$ using Maxent algorithm provides uniqueness to the study.Because of the suitable habitat, this species has been expanding at an alarming rate in CNP and its BZCF area. The invasion has severely damaging effects on young trees, shrubs, grasses in mostly mixed and riverine forests and grasslands. The result of this paper shows that the riverine forest areas prove to be the most suitable habitat for this weed. There is no known practical use for this weed. Very few control measures have been adopted and hence, no significant outputs are noticed which calls for an urgent requirement for strong control measures.

The areas predicted suitable but currently not occupied by the Mikania micrantha are the candidate areas to be considered for adopting prevention measures. Invasion distribution maps can be used as early detection tool and for the management of invasive species, which can help in minimizing the ecological significance and economic cost of invasions. Beside these, clarifying the exact region of invasive plants such as Mikania micrantha will be vital to develop ecological protocols for directing the conservation measures and to be able to conserve and foresee potential invasions in the future. 
The output of Maxent modelling is dependent mostly on the occurrence records, environmental layer and resolution at which the study is being conducted. By taking these factors into consideration, the Maxent model can further be used for predicting the potential invasion at various scales and for mapping potential distribution of other flora and fauna species as well.

\section{ACKNOWLEDGEMENT}

We acknowledge GIRC-Geomatics Project of Kathmandu University and International Center for Integrated Mountain Development (ICIMOD) for its financial contribution towards the achievement of the project. We wish to thank Kathmandu University, Department of Civil and Geomatics Engineering (DCGE) and Land Management Training Centre (LMTC) for their continuous guidance and supervision in successful completion of the project. Also, we owe great many thanks to the entire team of NTNC, BCC (National Trust for Nature Conservation, Biodiversity Conservation Center), Sauraha, Chitwan for their tremendous support and generosity during the field work in Chitwan National Park.

\section{REFERENCES}

Bhoju, D. R., Shrestha, B. B., \& Niraula, R. R. (2012). Study on Invasive Alien Species (IAS) as Drivers to Deforestation and Degradation of Forests in Different Physiographic Regions of Nepal. BS JV API/REDD Cell, Climate Change Unit MFSC.

DNPWC. (n.d.). Chitwan National Park. Retrieved from http://www.dnpwc.gov.np/protected_areas/details/chitwannational park on 04-10-2014.

Global Invasive Species Database (2014). Species profile: Mikania micrantha. Retrieved from http://www.iucngisd.org/gisd/species.php?sc=42 on 04-06-2014.

Gurevitch, J. and Padilla, D.K. (2004). Are invasive species a major cause of extinctions? Trends. Ecol. Evol. 19, 470-474.

IUCN. (2000). IUCN Guidelines for the Prevention of Biodiversity Loss due to Biological Invasion. Gland, Switzerland.

Kumar, S., \&Stohlgren, T. J. (2009). Maxent modeling for predicting suitable habitat for threatened and endangered tree Canacomyricamonticola in New Caledonia. Journal of Ecology and the Natural Environment, 1(4), 094-098.

Kunwar, R. M., \&Acharya, R. P. (2013). Impact Assessment of Invasive Plant Species in Selected Ecosystems of BhadaureTamagi VDC, Kaski, International Union for Conservation of Nature and Natural Resources, Lalitpur, Nepal.

Paudel, R. P. (2011). Insight Into Invasive Species (Mikania micrantha), Its Control Measures and Programmes in Nepal. The Initiation, 4, 115-119.

Pearson, R. G. (2007). Species' distribution modeling for conservation educators and practitioners. Synthesis. American Museum of Natural History, 1, 1-50.
Phillips, S. J., Anderson, R. P., \& Schapire, R. E. (2006). Maximum entropy modeling of species geographic distributions. Ecological modelling, 190(3), 231-259.

Ram, A. K. (2008). Impact of Mikania micrantha on Rhinoceros habitat in Chitwan National Park, Chitwan Nepal (Doctoral dissertation, Tribhuvan University).

Tiwari, S., Siwakoti, M., Adhikari, B. \& Subedi, K. (2005). An Inventory and Assessment of Invasive Alien Plant Species of Nepal, IUCN - The World Conservation Union, Nepal. viii+114 pp.

Yang, X. Q., Kushwaha, S. P. S., Saran, S., Xu, J., \& Roy, P. S. (2013). Maxent modeling for predicting the potential distribution of medicinal plant, Justicia adhatoda L. in Lesser Himalayan foothills. 